\title{
Distribution and Transport of Iron in Conidia of Colletotrichum musae in Relation to the Mode of Action of Germination Stimulants
}

\author{
By A. HADDEN GRAHAM $†$ AND DAVID B. HARPER* \\ Department of Agricultural and Food Chemistry, Queen's University of Belfast, Newforge Lane, \\ Belfast BT9 5PX, Northern Ireland, and Department of Agriculture, Northern Ireland
}

(Received 21 June 1982; revised 15 September 1982)

\begin{abstract}
Comparative studies on germination of conidia of Colletotrichum musae with low and normal iron contents indicated that in addition to lacking the normal requirement for a germination stimulant low-iron conidia germinated substantially faster. Parallel investigations on the iron flux in conidia during germination demonstrated that the presence of germination stimulants did not significantly influence iron uptake or release by conidia. In addition no major intracellular movement of iron between the organelle, wall and soluble fractions of conidia was detected. These findings imply that the action of chelating agents in promoting germination in conidia of $C$. musae involves the complexing of inhibitory iron at a site within the conidia, so releasing the germination mechanism. Selective accumulation of a germination stimulant (EDTA) within the organelle fraction during induction of germination in iron-replete conidia suggests that the site involved is located in this fraction, possibly on ribosomes. However, the marked differences observed between the relative dimensions of low-iron and iron-replete conidia could implicate the conidial wall as the site of iron complexed by chelating agents involved in stimulation of germination.
\end{abstract}

\section{INTRODUCTION}

Swinburne (1976) demonstrated that anthranilic acid in leachates of banana fruit stimulated germination of conidia of Colletotrichum musae, a pathogen responsible for anthracnose lesions on bananas. Harper \& Swinburne (1979) subsequently showed that anthranilic acid was metabolized by conidia of $C$. musae primarily to 2,3-dihydroxybenzoic acid (DHBA). The latter compound was found to be a more effective stimulant of germination than anthranilic acid both in terms of the concentration required to promote germination (Harper \& Swinburne, 1979) and also the length of time before onset of germination in the presence of the compound (Harper $e t$ al., 1980). It was therefore suggested that the activity of anthranilic acid as a germination stimulant could be attributed entirely to its conversion in vivo to DHBA rather than to any intrinsic activity.

Since DHBA and its conjugates are well known for their chelating properties, which enable them to play an important role in iron transport in bacteria (Lankford, 1973; Neilands, 1973), Harper et al. (1980) investigated the effect on germination of a number of synthetic metalcomplexing agents. Such compounds produced stimulation of conidial germination comparable to that observed with DHBA, suggesting that the chelating properties of the latter were indeed important in its biological role in C. musae. Although all of the chelating agents effective in promoting germination had a high affinity for iron, and siderophores (ligands which form very stable $\mathrm{Fe}^{3+}$ complexes) produced by a number of bacteria were also found to be highly stimulatory to germination (McCracken \& Swinburne, 1979, 1980), it was not possible on this

$\dagger$ Present address: Department of Agricultural Chemistry, University College, Belfield, Dublin 4, Ireland. 
evidence alone to conclude that the basis of their biological action in vivo was chelation with $\mathrm{Fe}^{3+}$ rather than another metal ion.

However, further investigations by Harper et al. (1980) convincingly established the involvement of iron in the germination process. It was observed that conidia of abnormally low iron content $\left[7 \mu \mathrm{g}(\mathrm{g} \text { dry } \mathrm{wt})^{-1}\right]$ produced by growing mycelium on iron-depleted medium $\left(60 \mathrm{ng} \mathrm{Fe}^{3+} \mathrm{ml}^{-1}\right)$ germinated freely in water without the normal requirement for a germination stimulant. Increased iron content in conidia was linearly correlated with a decrease in percentage germination. This inhibition of germination by iron was relieved at all conidial iron contents by anthranilic acid, in the presence of which germination remained uniformly high at levels similar to those of conidia of abnormally low iron content.

Speculating on the mode of action of chelating agents in promoting germination, Harper et al. (1980) concluded that in order to stimulate germination, they must first be incorporated into conidia where they cause removal of iron from a binding site so releasing the germination mechanism. The studies described in this paper were directed towards confirming this hypothesis, locating the binding site and determining, with the aid of ${ }^{59} \mathrm{Fe}$ and ${ }^{14} \mathrm{C}$-labelled germination stimulants, the fate of chelated iron, i.e. whether it is excreted from conidia, transported to a non-inhibitory site within the conidia or remains in situ in a chelated form which is ineffective in germination inhibition.

\section{METHODS}

Cultural conditions. Colletotrichum musae was isolated from anthracnose lesions on imported bananas and maintained on modified Cook's no. 2 agar medium (Swinburne, 1976). Conidia for experimental purposes were produced from mycelium grown in liquid shake cultures at $21^{\circ} \mathrm{C}$ on an asparagine/glucose-based medium of precisely defined iron concentration prepared as described by Harper et al. (1980). Conidia were harvested by filtering the contents of each flask through glass wool and centrifuging the resulting conidial suspension. Before use, conidia were washed by centrifugation and resuspension in water twice. The inoculum for liquid cultures was a conidial suspension harvested from mycelia grown for at least two generations in liquid culture medium containing $40 \mathrm{ng}$ iron $\mathrm{ml}^{-1}$.

Germination assay. Washed conidia were suspended (approximately $5 \times 10^{5}$ conidia $\mathrm{ml}^{-1}$ ) in water or anthranilic acid $\left(10^{-3} \mathrm{M}\right)$ and duplicate drops $(10 \mu \mathrm{l})$ were placed on glass slides and incubated in a moist chamber at $22^{\circ} \mathrm{C}$ for $24 \mathrm{~h}$. Counts for germination were made on at least 250 randomly selected conidia in each drop. To examine the time-course of germination in DHBA, washed conidia were mixed with a solution of DHBA $(5 \times$ $10^{-4} \mathrm{M}$ ) or water on a series of glass slides and incubated in a moist chamber at $22^{\circ} \mathrm{C}$. At regular intervals over the next $20 \mathrm{~h}$, slides were removed from the chamber and counts for germination made in the usual manner.

Iron determination. The concentration of iron in culture medium was determined by flameless atomic absorption using a Perkin Elmer 306 atomic absorption spectrophotometer fitted with an HGA 72 heated graphite atomizer. Conidial iron content was assayed by replacement of $10 \mathrm{ng}$ iron $\mathrm{ml}^{-1}$ in the growth medium by ${ }^{59} \mathrm{FeCl}_{3}[\mathrm{sp}$. act. $\left.5 \mu \mathrm{Ci} \mathrm{mg}^{-1}\left(185 \mathrm{kBq} \mathrm{mg}^{-1}\right)\right]$. Samples $(250 \mu \mathrm{l})$ of suspensions of washed conidia or conidial fractions were added to NE 250 scintillation fluid ( $5 \mathrm{ml}$, Nuclear Enterprises, Edinburgh, U.K.) and counted using an ICN Tracerlab Coru/matic 200 scintillation counter. The iron concentration of the suspension could be calculated from such counts and the known specific activity of iron in the culture medium before inoculation, since localization of iron within conidia did not lead to any apparent increase in quenching. Dry weights of samples of suspension were determined by drying at $80^{\circ} \mathrm{C}$ to constant weight and the iron concentration in conidia was expressed on a dry weight basis.

Separation of conidial components. Conidia containing ${ }^{59} \mathrm{Fe}$ or $\left[{ }^{14} \mathrm{C}\right] \mathrm{EDTA}$ were disrupted by a modification of the glass-bead method of Van Etten \& Freer (1978). Conidia ( $1 \mathrm{~g}$ dry wt) were suspended in $0 \cdot 1 \mathrm{M}$ phosphate buffer pH $6.5(10 \mathrm{ml})$ in a boiling tube $(45 \mathrm{ml})$ containing glass beads $(5 \mathrm{~g}$ Jencons grade $4,870-1275 \mu \mathrm{m}$ diam.). After cooling to $4{ }^{\circ} \mathrm{C}$, the sample was homogenized for $3 \mathrm{~min}$ with a vortex mixer at maximum speed. Following decantation of the homogenate the glass beads were washed three times with buffer $(5 \mathrm{ml})$. The homogenate and washings were combined, again cooled to $4{ }^{\circ} \mathrm{C}$ and subjected to sonication for $1 \mathrm{~min}$ using an MSE Mk2 ultrasonic disintegrator. Microscopic examination established the complete disruption of conidia by this technique.

Conidial walls were removed from the suspension by centrifugation $(500 \mathrm{~g}, 5 \mathrm{~min})$. The pellet was washed in buffer $(2 \times 10 \mathrm{ml})$ by resuspension and centrifugation $(500 \mathrm{~g}, 5 \mathrm{~min})$. Sedimentation of the cell organelles (nuclear material, ribosomes and mitochondria) from the combined supernatant and washings was achieved by centrifugation at $95000 \mathrm{~g}$ for $30 \mathrm{~min}$. The organelle pellet was again washed in buffer $(2 \times 10 \mathrm{ml})$ by resuspension and centrifugation $(95000 \mathrm{~g}, 30 \mathrm{~min})$. The washings were combined with the supernatant fraction to constitute the soluble fraction. Prior to determination of the iron or EDTA content by scintillation counting, the volume of each of the fractions was adjusted to $50 \mathrm{ml}$ with buffer. 
Measurement of conidial transport of iron and germination stimulants. Iron uptake during the initial stages of conidial germination was investigated by including ${ }^{59} \mathrm{Fe}$ in the germination medium. Conidia (approx. $5 \times$ $10^{5} \mathrm{ml}^{-1}$ ) were suspended in a germination medium $(100 \mathrm{ml})$ consisting of either distilled water or anthranilic acid $\left(10^{-3} \mathrm{M}\right)$, and ${ }^{59} \mathrm{FeCl}_{3}$ [sp. act. $250 \mathrm{nCi} \mathrm{mg}^{-1}\left(9 \cdot 2 \mathrm{kBq} \mathrm{mg}^{-1}\right)$ ] was added to each medium to give a final ferric iron concentration of $100 \mathrm{ng} \mathrm{ml}^{-1}$. The suspensions were incubated in conical flasks $(250 \mathrm{ml})$ at $22^{\circ} \mathrm{C}$ on an orbital shaker $(120$ r.p.m., eccentricity $2.5 \mathrm{~cm})$. Conidia were harvested by centrifugation $(1000 \mathrm{~g}, 3 \mathrm{~min})$ after various periods of incubation up to $8 \mathrm{~h}$ and washed with distilled water $(3 \times 30 \mathrm{ml})$ by resuspension and centrifugation. The radioactivities of the supernatant after incubation and of the conidial fraction following resuspension in distilled water $(100 \mathrm{ml})$ were determined. Iron uptake was expressed as a percentage of total iron in the incubation medium and on a conidial dry weight basis.

Iron release from conidia and intraconidial transport during the initial stages of germination were monitored using ${ }^{59} \mathrm{Fe}$-labelled conidia obtained by growth of the fungus on medium containing ${ }^{59} \mathrm{Fe}$ (see 'Iron determination'). Conidia were suspended $\left(5 \times 10^{5} \mathrm{ml}^{-1}\right)$ in distilled water or a solution of anthranilic acid $\left(10^{-3} \mathrm{M}\right)$ and incubated in conical flasks $(250 \mathrm{ml})$ on an orbital shaker as previously described for various periods up to $8 \mathrm{~h}$. Conidia were harvested, washed in distilled water $(3 \times 30 \mathrm{ml})$ by centrifugation $(1000 \mathrm{~g}, 3 \mathrm{~min})$ and resuspension. The radioactivities of the incubation medium and the conidia after resuspension in distilled water ( $100 \mathrm{ml})$ were measured and iron release expressed as a percentage of total conidial iron. In some experiments, before assay of iron, conidia were separated into components as described above.

Conidial uptake and localization of $\left[{ }^{14} \mathrm{C}\right]$ EDTA employed as a germination stimulant were investigated by suspending conidia in a solution of $\left[{ }^{14} \mathrm{C}\right]$ EDTA $\left[100 \mathrm{ml}, 5 \times 10^{-4} \mathrm{M}\right.$, sp. act. $\left.60 \mathrm{nCi} \mathrm{mg}^{-1}\left(2 \cdot 2 \mathrm{kBq} \mathrm{mg}^{-1}\right)\right]$. Suspensions were incubated in conical flasks in the usual manner at $22{ }^{\circ} \mathrm{C}$ for various periods. Conidia were then harvested and washed in water $(3 \times 30 \mathrm{ml})$ by centrifugation $(1000 \mathrm{~g}, 3 \mathrm{~min})$ and resuspension. The radioactivities of the incubation medium and the conidia after resuspension in distilled water $(100 \mathrm{ml})$ were measured and the ED'T A content of conidia expressed on a dry weight basis. Localization of $\left[{ }^{14} \mathrm{C}\right] \mathrm{EDT}$ A in conidia was determined by separation of cellular components and assay of each fraction individually.

Measurement of conidial dimensions. Conidial dimensions were examined using a Wild M20 photographic microscope. Duplicate drops of conidial suspensions stained with acid fuchsin were placed on glass slides and two photograhs taken of each drop. Measurements on the developed film were taken of at least 50 randomly selected conidia in each drop and were standardized against a photograph of a calibrated slide. The experiment was repeated five times using conidia from different isolates of $C$. musae, and mean values of the dimensions of conidia grown under different iron regimens compared using a $t$-test.

Chemicals. ${ }^{59} \mathrm{FeCl}_{3}$ in solution in $0 \cdot 1 \mathrm{M}-\mathrm{HCl}$ was supplied by Amersham. Stock solutions containing $20 \mu \mathrm{g}$ iron $\mathrm{ml}^{-1}$ [sp. act. $5 \mu \mathrm{Ci} \mathrm{mg}^{-1}\left(185 \mathrm{kBq} \mathrm{mg}^{-1}\right)$ ] were prepared by dilution with $0.01 \mathrm{M}-\mathrm{HCl}$. Ethylenediamine tetra-[2${ }^{14} \mathrm{C}$ ]acetic acid [sp. act. $281 \mu \mathrm{Ci} \mathrm{mg}-1\left(10.4 \mathrm{MBq} \mathrm{mg}^{-1}\right)$ ] was obtained as the sodium salt in aqueous solution from the same source. Aqueous solutions $\left(5 \times 10^{-4} \mathrm{M}\right)$ for experimental use were prepared with a specific activity of $60 \mathrm{nCi} \mathrm{mg} \mathrm{mg}^{-1}\left(2 \cdot 2 \mathrm{kBq} \mathrm{mg}^{-1}\right)$ by dilution with unlabelled compound.

\section{RESULTS AND DISCUSSION}

\section{Influence of iron concentration in the culture medium on condial germination}

Although Harper et al. (1980) clearly demonstrated an inverse relationship between conidial germination in water and the iron concentration of the culture medium on which the conidia were produced, the study was confined to conidia of one fungal isolate and media iron concentrations from 40 to $500 \mathrm{ng} \mathrm{ml}^{-1}$. In view of possible variations in germination behaviour between different fungal isolates of $C$. musae, the investigation was extended to three different isolates of the fungus grown on media with iron concentrations from 60 to $1000 \mathrm{ng} \mathrm{ml}^{-1}$. Figure 1 shows the percentage germination in water and anthranilic acid of conidia grown in media with various iron concentrations. The results confirm the previous observations of Harper et al. (1980) at iron concentrations below $500 \mathrm{ng} \mathrm{ml}^{-1}$ and it is evident that a similar germination pattern extends to iron concentrations up to $1000 \mathrm{ng} \mathrm{ml}^{-1}$.

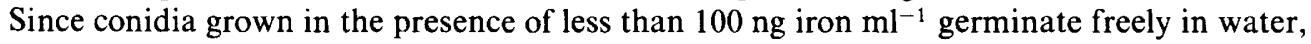
any influence of anthranilic acid on metabolism in these conidia prior to germination cannot be attributed to the stimulatory effects of the compound on germination of the conidia. However, as the presence of anthranilic acid stimulates germination of conidia harvested from a medium containing $500 \mathrm{ng}$ iron $\mathrm{ml}^{-1}$, any biochemical changes in such conidia prior to germination that are not observed in conidia from the lower-iron medium are probably associated with the process by which germination is induced by the stimulant. Subsequent experiments described in this paper therefore comprise a comparative study of iron-replete conidia (produced on medium 


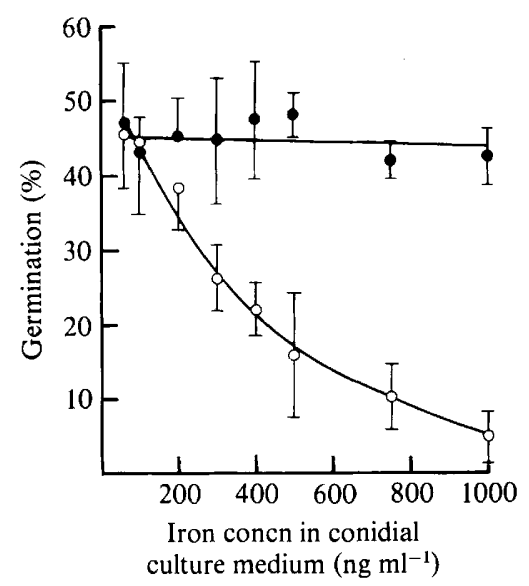

Fig. 1

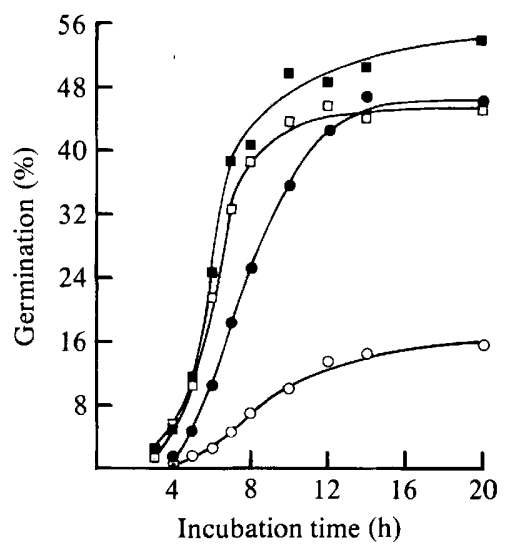

Fig. 2

Fig. 1. Influence of iron concentration in the culture medium on germination of conidia of Colletotrichum musae in water $(O)$ and in $10^{-3} \mathrm{M}$-anthranilic acid $(O)$. Values given are means \pm S.E.M.

Fig. 2. Rate of germination of iron-replete and low-iron conidia from Colletotrichum musae. Data indicate rates for iron-replete conidia in $5 \times 10^{-4} \mathrm{M}$-DHBA $(O)$ and in water $(O)$, and for low-iron conidia in $5 \times 10^{-4} \mathrm{M}$-DHBA ( $\square$ ) and in water $(\square)$.

containing $500 \mathrm{ng}$ iron $\mathrm{ml}^{-1}$ ) and low-iron conidia (produced on medium containing $60 \mathrm{ng}$ iron $\mathrm{ml}^{-1}$ ) in relation to various aspects of germination and transport of both iron and germination stimulants.

\section{Comparison of rate of germination of iron-replete and low-iron conidia}

Rates of germination of iron-replete and low-iron conidia in water and in a solution of DHBA $\left(5 \times 10^{-4} \mathrm{M}\right)$ are shown in Fig. 2. Conidia from low-iron medium showed a similar pattern of germination in both water and a solution of DHBA. Germination began after $3 \mathrm{~h}$ incubation and attained a maximum after $10 \mathrm{~h}$. Iron-replete conidia in the presence of DHBA only began to germinate after about $5 \mathrm{~h}$ incubation and germination did not achieve the same percentage as that in low-iron conidia until $13 \mathrm{~h}$ had elapsed. As previously noted, such conidia only germinate poorly in water, germination not exceeding $15 \%$ after $14 \mathrm{~h}$. The pattern of germination of ironreplete conidia is similar to that previously reported for conidia harvested from solid medium (Harper et al., 1980), although in general conidia from liquid media only attained germination levels of about $75 \%$ of those found for their counterparts grown on solid medium. This difference can probably be attributed to some loss of viability through leaching of endogenous nutrients from conidia into the culture medium during growth under the former conditions.

The 2 to $3 \mathrm{~h} \mathrm{lag}$ in germination between the low-iron conidia which germinate freely in water and the iron-replete conidia that only germinate in response to the presence of a germination stimulant suggests that, whilst a biochemical change (induced by the germination stimulant) must occur in iron-replete conidia before germination can ensue, such a change is not necessary or has previously occurred in low-iron conidia. This explanation is consistent with the conclusion of Harper et al. (1980) that iron acts as an inhibitor of germination and that germination stimulants release conidia from such inhibition by chelating iron.

\section{Conidial iron uptake and release during germination}

Horowitz et al. (1976) reported that, when conidia of Neurospora crassa were exposed to water with an activity of less than 0.95 they lost a substance essential for germination. This germination factor was identified as a siderophore (or iron-transport compound) and it was concluded that the germination process was delayed or inhibited as a result of iron deficiency if conidia had no mechanism for concentrating iron from the environment. If iron has an 
Table 1. Iron uptake during germination by conidia of Colletotrichum musae grown in media of normal and low iron status

$\begin{array}{cccc}\begin{array}{c}\text { Incubation } \\ \text { time (h) }\end{array} & \begin{array}{c}\text { Iron content of } \\ \text { growth medium }\left(\mathrm{ng} \mathrm{ml}^{-1}\right)\end{array} & \begin{array}{c}\text { Incubation } \\ \text { medium* }\end{array} & \left.\begin{array}{c}\text { Iron uptake by } \\ \text { conidia [ng (mg dry wt) }\end{array}{ }^{-1}\right]_{\dagger} \\ 2 & 60 & \mathrm{Fe} & 639 \\ & 60 & \mathrm{Fe}+\mathrm{AA} & 556 \\ 500 & \mathrm{Fe} & 324 \\ 500 & \mathrm{Fe}+\mathrm{AA} & 333 \\ 4 & 60 & \mathrm{Fe} & 685 \\ & 60 & \mathrm{Fe}+\mathrm{AA} & 685 \\ & 500 & \mathrm{Fe} & 347 \\ & 500 & \mathrm{Fe}+\mathrm{AA} & 338\end{array}$

* Fe indicates $\mathrm{FeCl}_{3}\left(100 \mathrm{ng} \mathrm{ml}^{-1}\right)$; AA indicates anthranilic acid $\left(10^{-3} \mathrm{M}\right)$.

$\dagger$ Means of three experiments using conidia from the same fungal isolate.

Table 2. Iron release during germination by conidia of Colletotrichum musae from media of normal and low-iron status

$\begin{array}{cccc}\begin{array}{c}\text { Incubation } \\ \text { time }(\mathrm{h})\end{array} & \begin{array}{c}\text { Iron content of } \\ \text { growth medium }\left(\mathrm{ng} \mathrm{ml}^{-1}\right)\end{array} & \begin{array}{c}\text { Anthranilic } \\ \text { acid }\left(10^{-3} \mathrm{M}\right)\end{array} & \begin{array}{c}\text { Conidial iron } \\ \text { released }(\%)^{*}\end{array} \\ 4 & 60 & - & 0 \cdot 9 \\ & 60 & + & 0 \cdot 7 \\ & 500 & - & 1 \cdot 3 \\ 8 & 500 & - & 0 \cdot 8 \\ & 60 & + & 0.3 \\ & 60 & - & 0.4 \\ & 500 & + & 0 \cdot 7 \\ & 500 & - & 0 \cdot 5\end{array}$

* Means of three experiments using conidia from the same fungal isolate.

inhibitory role in germination of C. musae as postulated by Harper et al. (1980), it is difficult to envisage a basis for the stimulatory effect of chelating agents on germination which involves transport of iron from the environment into conidia as in $N$. crassa. Nevertheless it is possible that conidia from low-iron media germinate readily in the absence of germination stimulant simply because growth under low-iron conditions induces acquisition of an iron-uptake mechanism which replaces the normal requirement for a germination stimulant.

Uptake of iron from solution by iron-replete and low-iron conidia in the presence and absence of anthranilic acid was therefore measured after incubation periods of 2 and $4 \mathrm{~h}$ (Table 1). Both iron-replete and low-iron conidia absorbed substantial quantities of iron from their environment after $2 \mathrm{~h}$ incubation, but low-iron conidia incorporated almost twice that absorbed by ironreplete conidia. However, anthranilic acid did not significantly influence iron assimilation by conidia of either iron status. Thus stimulation of germination by anthranilic acid and chelating agents is apparently not a result of increased iron uptake. This conclusion is in accord with the inhibitory role for iron suggested by Harper et al. (1980) and also the observation of McCracken \& Swinburne (1979) that only the desferri form of siderophores promoted germination. The greater iron uptake noted in low-iron conidia probably reflects an increased availability of free metal-ion binding sites in such conidia. Furthermore, double-labelling experiments with ironreplete conidia using both $\left[{ }^{3} \mathrm{H}\right]$ anthranilic acid and ${ }^{59} \mathrm{FeCl}_{3}$ have indicated that the presence of iron influenced assimilation of anthranilic acid only to a comparatively minor extent (Graham, 1981). It is thus clear that, although iron uptake can occur prior to germination, it is entirely unrelated to the uptake and action of germination stimulants.

If chelating agents act as germination stimulants by removing iron from a binding site within the conidia, so initiating the germination process, such chelated iron may be transported out of conidia prior togermination. Losses of iron from washed ${ }^{59} \mathrm{Fe}-$ labelled conidia derived from media of either high or low iron status were therefore monitored during germination (Table 2). 
Table 3. Influence of conidial iron status on the iron content of conidial fractions from Colletotrichum musae

\begin{tabular}{|c|c|c|c|c|}
\hline \multirow{2}{*}{$\begin{array}{l}\text { Iron content of } \\
\text { growth medium (ng } \mathrm{ml}^{-1} \text { ) }\end{array}$} & \multirow{2}{*}{$\begin{array}{l}\text { Iron content of } \\
\text { conidia }\left[\mu \mathrm{g}(\mathrm{g} \text { dry } w t)^{-1}\right]\end{array}$} & \multicolumn{3}{|c|}{$\begin{array}{l}\text { Iron content of conidial fractions } \\
{\left[\mu \mathrm{g}(\mathrm{g} \text { dry wt conidia })^{-1}\right]^{*}}\end{array}$} \\
\hline & & Wall & Organelle & Soluble \\
\hline 60 & 6.9 & $4 \cdot 2(60 \cdot 9)$ & $0 \cdot 51(7 \cdot 2)$ & $2 \cdot 2(31 \cdot 9)$ \\
\hline 100 & $10 \cdot 3$ & $5.8(51.7)$ & $0.75(6.8)$ & $3.8(36.9)$ \\
\hline 200 & $21 \cdot 4$ & $11 \cdot 6(54.2)$ & $1.5 \quad(7.0)$ & $8 \cdot 3(38 \cdot 8)$ \\
\hline 300 & $24 \cdot 1$ & $10 \cdot 0(41 \cdot 5)$ & $1.7 \quad(7.0)$ & $12 \cdot 4(51 \cdot 5)$ \\
\hline 400 & $40 \cdot 3$ & $14 \cdot 3(35 \cdot 5)$ & $2.4 \quad(6.0)$ & $23.6(58.5)$ \\
\hline 500 & $54 \cdot 0$ & $14.8(27.4)$ & $3 \cdot 3 \quad(6 \cdot 1)$ & $35 \cdot 9(66 \cdot 5)$ \\
\hline 750 & $57 \cdot 5$ & $16.0(27.8)$ & $4.9 \quad(8.5)$ & $36.6(63.7)$ \\
\hline 1000 & $73 \cdot 0$ & $19 \cdot 4(26 \cdot 6)$ & $6 \cdot 1 \quad(8.4)$ & $47.5(65.0)$ \\
\hline
\end{tabular}

* Means of three experiments using conidia from the same fungal isolate; figures in parentheses show iron content expressed as a percentage of total conidial iron.

Iron release prior to germination was relatively small and did not exceed $1.3 \%$ of total conidial iron. The iron lost during the first $4 \mathrm{~h}$ of incubation was partly reabsorbed during the next $4 \mathrm{~h}$, possibly to satisfy the nutritional requirements of the germinating conidia. No significant difference was observed between iron release from conidia incubated in the presence and absence of anthranilic acid, nor did the iron status of the conidia appear to have any appreciable influence on the percentage of iron released. Thus, if stimulation of germination in iron-replete conidia by anthranilic acid and chelating agents is caused by removal of iron from an intraconidial binding site, the chelated iron is certainly not transported out of the conidia into the medium by such compounds. Therefore, either such transport must be restricted to intraconidial movement or alternatively inhibitory iron must remain in situ in a chelated form which is ineffective in inhibition of germination.

\section{Distribution of iron within conidia of Colletotrichum musae}

The distribution of iron between various fractions from conidia with different iron contents was measured (Table 3). As total conidial iron content increased so did the iron of each fraction, though not in identical proportions. In low-iron conidia, iron was found predominantly in walls, but as the total conidial iron content increased from 6.9 to $54.0 \mu \mathrm{g}$ (g dry wt) ${ }^{-1}$ so the proportion in this fraction decreased from $61 \%$ to $27 \%$, probably as a consequence of the increasing degree of saturation of available binding sites associated with the cell-wall components. Chitin, which represents a major constituent of conidial walls, is known to be particularly effective at chelating iron (Muzzarelli, 1973).

The proportion of iron in organelles remained constant at about $7 \%$ of total conidial iron regardless of the overall iron status of conidia. Nuclear material and respiratory proteins in mitochondria are probably the major source of iron in this fraction. The soluble iron fraction, which corresponds to iron located in the cytoplasm (possibly as ferritin-like aggregates as described in Phycomyces sp. by David \& Easterbrook, 1971) together with labile iron leached from walls or organelles during fractionation, increased from $32 \%$ of total conidial iron in lowiron conidia to $65 \%$ in iron-replete conidia.

The data in Fig. 1 and Table 3 were used to examine the effect of the iron content of each conidial fraction on germination of intact conidia in water (see Fig. 3) in an attempt to locate the site at which iron binds and inhibits germination. The iron content of each of the conidial fractions showed an inverse relationship with germination, a finding not unexpected in view of the observation by Harper et al. (1980) of a high inverse correlation between total conidial iron content and germination. As the correlation coefficient for each fraction exceeds $0.96(P<$ $0.001)$ this treatment of the data does not provide any useful information as to the site of inhibition. 


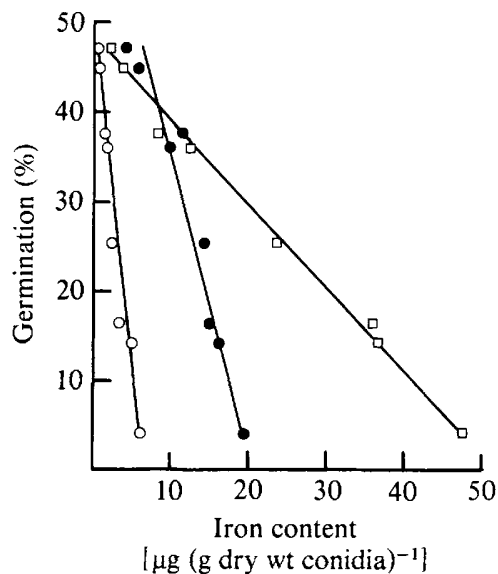

Fig. 3. Influence of iron content in conidial fractions of Colletotrichum musae on conidial germination The data relate germination to iron contents of the organelles $(\bigcirc)$, walls $(\bigcirc)$, and soluble fraction $(\square)$.

Table 4. Movement of iron during germination of conidia of Colletotrichum musae

\begin{tabular}{|c|c|c|c|c|c|}
\hline \multirow{2}{*}{$\begin{array}{l}\text { Incubation } \\
\text { time (h) }\end{array}$} & \multirow{2}{*}{$\begin{array}{l}\text { Iron content of } \\
\text { parent medium } \\
\quad\left(\mathrm{ng} \mathrm{ml} \mathrm{m}^{-1}\right)\end{array}$} & \multirow{2}{*}{$\begin{array}{l}\text { Anthranilic } \\
\text { acid }\left(10^{-3} \mathrm{M}\right)\end{array}$} & \multicolumn{3}{|c|}{$\begin{array}{l}\text { Iron content of conidial fraction } \\
{\left[\mu \mathrm{g}(\mathrm{g} \text { dry wt conidia })^{-1}\right]^{*}}\end{array}$} \\
\hline & & & Wall & Organelle & Soluble \\
\hline 0 & $\begin{array}{r}60 \\
500\end{array}$ & $\begin{array}{l}- \\
-\end{array}$ & $\begin{array}{r}6 \cdot 5 \\
15 \cdot 5\end{array}$ & $\begin{array}{l}0.70 \\
3.8\end{array}$ & $\begin{array}{r}3 \cdot 2 \\
32 \cdot 0\end{array}$ \\
\hline 2 & $\begin{array}{r}60 \\
60 \\
500 \\
500\end{array}$ & $\begin{array}{l}- \\
+ \\
+ \\
+\end{array}$ & $\begin{array}{r}6 \cdot 4 \\
6 \cdot 3 \\
15 \cdot 3 \\
15 \cdot 0\end{array}$ & $\begin{array}{l}0 \cdot 71 \\
0 \cdot 70 \\
3 \cdot 7 \\
3 \cdot 8\end{array}$ & $\begin{array}{r}3 \cdot 3 \\
3 \cdot 6 \\
33 \cdot 2 \\
34 \cdot 1\end{array}$ \\
\hline 4 & $\begin{array}{r}60 \\
60 \\
500 \\
500\end{array}$ & $\begin{array}{l}- \\
+ \\
+ \\
+\end{array}$ & $\begin{array}{r}6 \cdot 2 \\
6 \cdot 2 \\
15 \cdot 0 \\
14 \cdot 2\end{array}$ & $\begin{array}{l}0 \cdot 70 \\
0 \cdot 69 \\
3 \cdot 9 \\
3 \cdot 8\end{array}$ & $\begin{array}{r}3 \cdot 3 \\
3 \cdot 5 \\
33 \cdot 6 \\
34 \cdot 8\end{array}$ \\
\hline
\end{tabular}

* Mean of three experiments using conidia from the same fungal isolate.

\section{Intraconidial movement of iron during germination}

In order to ascertain whether intraconidial transport of iron occurred during induction of germination by germination stimulants, iron-replete and low-iron conidia were separated into cellular fractions at various stages of germination and the iron content of each fraction measured (Table 4). No major intracellular movement of iron in conidia of either iron status was observed during the first $8 \mathrm{~h}$ of incubation. A minor net movement of iron from the wall to the soluble fraction was apparent during the first $4 \mathrm{~h}$ incubation, but this occurred in both iron-replete and low-iron conidia regardless of the presence of anthranilic acid and was therefore not thought significant in relief of germination inhibition. Some of the loss from conidial walls can be accounted for by iron release into the incubation medium described in Table 2 . These findings suggest that intraconidial transport of iron by chelating agents during germination does not occur. Instead it would appear that iron found at the presumed inhibitory site and displaced by complexing with a chelating agent remains in situ in a chelated form which cannot inhibit germination. Nevertheless, the results in Table 4 do not preclude the possibility that limited transport may occur within the conidial fraction concerned.

\section{Distribution of EDTA employed as a germination stimulant in conidia of Colletotrichum musae}

If iron involved in inhibition of germination in iron-replete conidia remains in situ after displacement from the binding site by a chelating agent, the distribution of the chelating agent within the conidia during germination induction should provide an indication of the site of 
Table 5. Uptake of EDTA into various fractions during germination of conidia of Colletotrichum musae

\begin{tabular}{|c|c|c|c|c|}
\hline \multirow{2}{*}{$\begin{array}{l}\text { Incubation } \\
\text { time (h) }\end{array}$} & \multirow{2}{*}{$\begin{array}{l}\text { Iron content of parent } \\
\text { medium (ng ml-1) }\end{array}$} & \multicolumn{3}{|c|}{$\begin{array}{l}\text { EDTA content of conidial fraction } \\
{\left[\mu \mathrm{g}(\mathrm{mg} \text { dry wt conidia })^{-1}\right]^{*}}\end{array}$} \\
\hline & & Walls & Organelles & Soluble \\
\hline 2 & $\begin{array}{r}60 \\
500\end{array}$ & $\begin{array}{l}- \\
-\end{array}$ & $\begin{array}{l}0.2(8) \\
2.9(37)\end{array}$ & $\begin{array}{l}2 \cdot 4(92) \\
5 \cdot 0(63)\end{array}$ \\
\hline 4 & $\begin{array}{r}60 \\
500\end{array}$ & $\begin{array}{l}- \\
0 \cdot 5(5)\end{array}$ & $\begin{array}{l}0.4(11) \\
3 \cdot 7(38)\end{array}$ & $\begin{array}{l}3.3(89) \\
5 \cdot 5(57)\end{array}$ \\
\hline 8 & $\begin{array}{r}60 \\
500\end{array}$ & $\begin{array}{l}0.9(10) \\
1.0(8)\end{array}$ & $\begin{array}{l}1.9(23) \\
5 \cdot 4(46)\end{array}$ & $\begin{array}{l}5 \cdot 6(67) \\
5 \cdot 4(46)\end{array}$ \\
\hline
\end{tabular}

* Means of three experiments using conidia from the same fungal isolate; figures in parentheses show EDTA content expressed as a percentage of total conidial EDTA.

inhibition. Differences between chelating agent distribution in germination stimulantrequiring, iron-replete conidia and freely-germinating, low-iron conidia should be of particular significance in this respect. During the first $4 \mathrm{~h}$ of conidial incubation the wall fraction did not contain appreciable quantities of EDTA in either iron-replete nor low-iron conidia (Table 5). Only $5 \%$ of total conidial EDTA was detected in the walls even in iron-replete conidia after this period of time, despite the comparatively large proportion of total conidial iron present in this fraction in conidia of both normal and low iron status (see Table 3). However, this observation must be considered in the context of the likelihood that much of the iron, and indeed other cations, in the wall is complexed with chitin and is not available for chelation with EDTA (Muzzarelli, 1973). The absence of EDTA in walls makes it unlikely that iron in this fraction was involved in inhibition of germination, though results reported below do not entirely eliminate this possibility.

During the first $2 \mathrm{~h}$ incubation, EDTA uptake in low-iron conidia was mainly into the soluble fraction, with only $8 \%$ passing into the organelle fraction. Little change in this ratio was apparent after $4 \mathrm{~h}$ incubation. In contrast, although after $2 \mathrm{~h}$ incubation of iron-replete conidia the concentration of EDTA in the soluble fraction was only double that of the low-iron conidia, the concentration of EDTA in the organelle fraction exhibited an approximately 15-fold increase relative to that of the low-iron conidia, resulting in almost $40 \%$ of the total conidial EDTA being found in this fraction. This increase is especially significant when considered in the light of the observations in Table 3 which demonstrate that the percentage of total conidial iron present in the organelle fraction is similar in iron-replete and low-iron conidia. Such selective accumulation of EDTA in the organelle fraction in iron-replete conidia which require a germination stimulant suggests that iron in this fraction is particularly susceptible to binding by EDTA and so may represent the iron involved in inhibition of germination.

The involvement of iron in mitochondrial metabolism and the reported control by iron of ribosomal translation (Downer et al., 1970; Zahringer et al., 1976) suggest potential sites within the organelle fraction where control of germination by iron might be exercised. Regulation at the ribosomal level represents a particularly attractive posssibility, as RNA transcription and de novo synthesis of proteins are the first detectable biochemical changes occurring in germinating conidia of various fungal species (Barash et al., 1967; Shepherd et al., 1980).

Hall \& Axelrod (1977) reported that including EDTA during homogenization of young mycelia of Aspergillus nidulans increased the susceptibility of DNA to hydrolysis with hot perchloric acid, and they considered that this was due to the complexing of ferric ions in the homogenate which would otherwise inhibit hydrolysis. Removal of ferric ions from DNA of $A$. nidulans was shown to occur in vivo immediately prior to cell division during sporulation (Hall \& Axelrod, 1978). A similar effect might explain the requirement for germination stimulants in $C$. musae. However, Graham (1981) demonstrated that whilst EDTA did increase the susceptibility of conidial DNA to acid hydrolysis in this organism, there was no change in 
Table 6. Influence of iron status on dimensions of conidia of Colletotrichum musae

\begin{tabular}{|c|c|c|c|c|}
\hline \multirow[b]{2}{*}{$\begin{array}{l}\text { Dimension of } \\
\text { conidia }\end{array}$} & \multicolumn{2}{|c|}{ Conidial iron status } & \multirow[b]{2}{*}{ S.E.M. } & \multirow[b]{2}{*}{ Significance } \\
\hline & $\begin{array}{l}\text { Low (from medium } \\
\text { with } 60 \mathrm{ng} \mathrm{Fe}^{3+} \mathrm{ml}^{-1} \text { ) }\end{array}$ & $\begin{array}{l}\text { Replete (from medium } \\
\text { with } 500 \mathrm{ng} \mathrm{Fe}^{3+} \mathrm{ml}^{-1} \text { ) }\end{array}$ & & \\
\hline Width $(\mu \mathrm{m})$ & $4 \cdot 55$ & $4 \cdot 03$ & 0.410 & $* * *$ \\
\hline Length $(\mu \mathrm{m})$ & $14 \cdot 21$ & $15 \cdot 45$ & $2 \cdot 86$ & $* * *$ \\
\hline Length : width ratio & 2.98 & $4 \cdot 11$ & 0.05 & $* * *$ \\
\hline
\end{tabular}

hydrolysability during germination. It seems unlikely therefore that the effect of germination stimulants is at the DNA level.

\section{Influence of conidial iron status on dimensions of conidia of Colletotrichum musae}

Conidia with higher iron contents were significantly longer and narrower than their lower iron counterparts (Table 6) though the dimensions of both were compatible with values reported by Sutton \& Waterston (1970) for conidia of this species i.e. 3-6 $\times 11-17 \mu \mathrm{m}$. The value for the axial ratio (length : width) of 2.98 for low-iron conidia contrasts with 4.11 for iron-replete conidia and is indicative of the markedly more spherical shape of the former. Whether this morphological difference is important with regard to the relative responses of such conidia to germination stimulants is uncertain. It is possible to envisage iron acting as a crosslinking agent between the polymeric chains of chitin comprising the wall and so strengthening the structure in a manner analogous to stabilization of pectin gels by calcium ions (deMan, 1980). Greater mechanical strength associated with higher iron content would permit the attainment of the more cylindrical form observed in iron-replete conidia. Stimulation of germination in high-iron conidia by chelating agents could then be explained in terms of the removal of chitin-bound iron during passage of the chelating agent through the wall, a process resulting ultimately in a decrease in the mechanical strength sufficient to allow germ-tube emergence. An enzymemediated weakening of the spore coat has previously been considered an essential event in germination of spores of other fungi (Powell \& Strange, 1953; Leighton \& Stock, 1970). The small proportion of iron released from the walls prior to germination would seem to militate against such a hypothesis. However, Swinburne (1976) reported that germ tubes normally emerge from specific sites which constitute only a small fraction of the conidial surface. Transport of iron from such localized morphologically distinct sites only might therefore explain the comparatively small release of iron during germination. Nevertheless, if induced weakening of the wall by removal of iron is confined to such small areas it seems unlikely that it could affect the dimensions of conidia grown under different iron regimens to the extent found.

We wish to thank Dr T. Swinburne for helpful discussions and Dr D. Kilpatrick of the Biometrics Division, Department of Agriculture, N. Ireland for advice on statistical analysis. A. H. Graham was the recipient of a post graduate fellowship awarded by the Thomas Henry Trust.

\section{REFERENCES}

Barash, I., Conway, M. L. \& Howard, D. H. (1967) Carbon catabolism and synthesis of macromolecules during spore germination of Microsporum gypseum. Journal of Bacteriology 93, 656-662.

David, C. N. \& EASTERBROOK, K. (1971). Ferritin in the fungus Phycomyces. Journal of Cell Biology 48, 15-28.

DEMAN, J. M. (1980). Principles in Food Chemistry. pp. 164. Westport, Connecticut: AVI.

Downer, D. N., Davis, W. B. \& BYers, B. R. (1970). Repression of phenolic acid synthesizing enzymes and its relation to iron uptake in Bacillus subtilis. Journal of Bacteriology 101, 181-187.

Graham, A. H. (1981). Studies on the role of iron in the germination of conidia of Colletotrichium musae. Ph.D. thesis, The Queen's University of Belfast, N. Ireland.

HaLL, N. E. L. \& Axelrod, D. E. (1977). Interference of cellular ferric ions with DNA extraction and the application to methods of DNA determination. Analytical Biochemistry 79, 425-430.

HALl, N. E. L. \& AXeLrod, D. E. (1978). Sporulation 
competence in Aspergillus nidulans: a role for iron in development. Cell Differentiation 7, 73-82.

HARPER, D. B. \& Swinburne, T. R. (1979). 2,3Dihydroxybenzoic acid and related compounds as stimulants of germination of conidia of Colletotrichum musae (Berk. and Curt.) Arx. Physiological Plant Pathology 14, 363-370.

HARPER, D. B., SWINBURNe, T. R., MoORe, S. K., Brown, A. E. \& Graham, H. (1980). A role for iron in germination of conidia of Colletotrichum musae. Journal of General Microbiology 121, 169-174.

Horowitz, N. H., Charlang, G., Horn, G. \& Williams, N. P. (1976). Isolation and identification of the conidial germination factor of Neurospora crassa. Journal of Bacteriology 127, 135-140.

LANKFORD, C. E. (1973). Bacterial assimilation of iron. CRC Critical Reviews in Microbiology 2, 273-331.

Leighton, T. J. \& Stock, J. J. (1970). Biochemical changes during fungal sporulation and spore germination. Journal of Bacteriology 101, 931-940.

McCracken, A. R. \& Swinburne, T. R. (1979). Siderophores produced by saprophytic bacteria as stimulants of germination of conidia of Colletotrichum musae. Physiological Plant Pathology 15, 331340.

MCCracken, A. R. \& Swinburne, T. R. (1980). Effect of bacteria isolated from the surface of banana fruits on the germination of conidia of Colletotrichum musae (Berk. and Curt.) Arx. Transactions of the British Mycological Society 74, 18-20.

Muzzarelli, R. A. A. (1973). Natural Chelating Polymers, pp. 83-143. Oxford: Pergamon.

NeIlands, J. B. (1973). Microbial iron transport compounds. In Inorganic Biochemistry, pp. 167-202. Edited by G. Eichkorn. Amsterdam: Elsevier.

Powell, J. F. \& Strange, R. E. (1953). Biochemical changes occurring during the germination of bacterial spores. Biochemical Journal 54, 205-209.

ShePherd, M. G., Yin, C. Y., RaM, S. P. \& Sullivan, P. A. (1980). Germ tube induction in Candida albicans. Canadian Journal of Microbiology 26, 21-26.

Sutton, B. C. \& Waterston, J. M. (1970). Description of pathogenic fungi and bacteria, no. 222: Colletotrichum musae. London: Commonwealth Mycological Institute.

SwINBURNE, T. R. (1976). Stimulants of germination and appressoria formation by Colletotrichum musae (Berk. and Curt.) Arx. in banana leachate. Phytopathologische Zeitschrift 87, 74-80.

VAN EtTen, J. L. \& Freer, S. N. (1978). Simple procedure for disruption of fungal spores. Applied and Environmental Microbiology 35, 622-623.

ZAHRINGER, J., BALIGA, B. S. \& MuNRo, H. N. (1976). Novel mechanism for translational control in regulation of ferritin synthesis by iron. Proceedings of the National Academy of Sciences of the United States of America 73, 857-861. 